\title{
CDH3 Positive
}

National Cancer Institute

\section{Source}

National Cancer Institute. CDH3 Positive. NCI Thesaurus. Code C133703.

Indicates that $\mathrm{CDH} 3$ expression has been detected in a sample. 